Reproduktionsmedizin

2000 - 16: 155-167 @ Springer-Verlag 2000

Urologie

T. Diemer • D. Buchanan Hales • Department of Physiology and Biophysics, University of Illinois, Chicago

T. Diemer • M. Ludwig • Petra Huwe • W. Weidner • Urologische Klinik der Justus-Liebig-

Universitat Gießen

\title{
Urogenitale Infektionen beim Mann - können sie die Fertilität beeinflussen?
}

\section{Zusammenfassung}

Urogenitale Infektionen können die Fertilität des Mannes beeinflussen. Verschiedene pathophysiologische Konzepte haben sich aus experimentellen und klinischen Studien ergeben, welche die Wirkung urogenitaler Infektionen auf Spermatogenese und Spermienfunktion erklären können. Neuere Studien haben vor allen Dingen Entzündungsmediatoren evaluiert, die für spezifische molekulare Vorgänge im Infektionsgeschehen verantwortlich zeichnen. Aufgrund verbesserter Diagnostik und Klassifikationskriterien sind für die Zukunft sicher interessante, aussagekräftigere Studien zu erwarten.

\section{Schlüsselwörter}

Urogenitale Infektionen • Zytokine • Reaktive Sauerstoffverbindungen (ROS) • Spermatogenese $\cdot$ Steroidbiosynthese
E Erkrankungen sind als Ursache von Fertilitätsstörungen seit langer Zeit diskutiert worden. Hierbei spielen sowohl generalisierte akute und chronische entzündliche Erkrankungen als auch lokale Infektionen des Urogenitaltraktes des Mannes eine Rolle (Hales et al. 1999; Weidner et al. 1999). Auch heute noch findet sich bei etwa $15 \%$ aller Patienten mit dem Problem einer Fertilitätsstörung eine urogenitale Infektion als Ursache (Diemer u. Desjardins 1999). Akuten generalisierten Infektionen ist als Ursache der männlichen Infertilität stets wenig Beachtung geschenkt worden, da das unmittelbare Therapieziel bei Erkrankungen wie gramnegativer Sepsis und systemisch inflammatorischer Reaktion (SIR) natürlich auf das unmittelbare Überleben des Patienten konzentriert ist. Akute generalisierte Infektionen scheinen dabei vor allem testikulär auf die Steroidbiosynthese und Spermatogenese zu wirken, wobei sowohl die langfristigen Folgen für die Spermatogenese als auch die unmittelbare Auswirkung der Beeinträchtigung des endokrinen Kompartimentes des Hodens für den Verlauf der inflammatorischen Erkrankung wenig erforscht sind (Bosmann et al. 1996; Hales et al. 1999; Sam et al. 1999). Numerisch gesehen dürften diese Erkrankungen aber, wenn auch pathophysiologisch interessant, unter infertilen Patienten von untergeordneter Bedeutung sein.
Akute, klassische Urogenitalinfektionen wie akute Epididymitis, akute Prostatitis und Urethritis stellen meist eindeutige Krankheitsbilder dar, welche mit antibiotischer Therapie sicher $\mathrm{zu}$ beherrschen sind (Weidner et al. 1998; Weidner et al. 1999). Unmittelbares Therapieziel ist die Bekämpfung der akuten Infektion und Schmerzlinderung sowie eine Begrenzung des Gewebeschadens, verursacht durch immunologische Reaktionen (Weidner et al. 1998). Die postinfektiöse Pathologie nach akuten, putriden Infektionen ist häufig durch schwere strukturelle Gewebeveränderungen gekennzeichnet, welche die Verminderung der Reproduktionsfähigkeit eindeutig erklären können (Diemer u. Desjardins 1999). Schwieriger $\mathrm{zu}$ bewerten sind chronische urogenitale Infektionen oder infektionsassoziierte Syndrome, da pathomorphologische Veränderungen meist nicht evident sind und der gesamte Symptomkomplex selten eindeutig ist. In diesem Zusammenhang sind

Thorsten Diemer wird gegenwärtig von der Deutschen Forschungsgemeinschaft (DFG) im Rahmen eines DFG Forschungsstipendiums, Projekt Di-723/1-1, unterstützt

\section{T. Diemer}

Department of Physiology and Biophysics, University of Illinois at Chicago (UIC), 835 South Wolcott Avenue,

Chicago, IL 60612-7342, USA

e-mail: tdiemer@uic.edu 
Reproduktionsmedizin

2000 - 16: 155-167 @ Springer-Verlag 2000

T. Diemer • D. Buchanan Hales • M. Ludwig • P. Huwe $\cdot$ W. Weidner

\section{Urogenital infections in males - can they influence fertility?}

\begin{abstract}
Urogenital infections are established as hazards to male fertility. Various pathophysiological hypotheses have evolved from experimental and clinical studies, facilitating explanation of the effects of bacteria and immunological events on reproductive tissues. Numerous current studies have identified and evaluated infectious mediators accounting for specific molecular events in urogenital infections. Valuable studies can be expected to appear in the future due to improvements in diagnostic procedures and new classifications of urogenital infections.
\end{abstract}

\section{Keywords}

Urogenital infections $\bullet$ Cytokines $\cdot$ Reactive oxygen species (ROS) • Spermatogenesis • Steroidogenesis

\section{Urologie}

auch Infektionen des Ejakulates oder der akzessorischen Geschlechtsdrüsen zu nennen, welche geringe oder nahezu keine Symptomatik verursachen, aber dennoch zytologisch, histologisch und bakteriologisch $\mathrm{zu}$ erkennen sind (z. B. einige Formen des Prostatitissyndromes, asymptomatische Bakteriospermie) (Ludwig et al. 1998; Weidner et al. 1999).

Bei der Bewertung mikrobiologischer Befunde des Ejakulates stellt sich zudem das Problem der Kontamination, worauf neuere Arbeiten eindrücklich hingewiesen haben (Schiefer 1998; Kim u. Goldstein 1999). Nur wenig ist über die Rolle von Viren im Rahmen von urogenitalen Infektionen bekannt und beschrieben worden. Einige tierexperimentelle Arbeiten sowie Studien an HIV-infizierten Patienten liefern jedoch interessante Hinweise über den Zusammenhang von viralen Infektionen und Infertilität, teilweise erklärt durch schwere, erworbene Störungen der Spermatogenese (Muciaccia et al. 1998; Muller et al. 1998).

Lokalisierte urogenitale Infektionen, vor allem Infektionen der akzessorischen Geschlechtsdrüsen des Mannes (MAGI), sind assoziiert mit der Vermehrung von Leukozyten im Ejakulat sowie erhöhten Spiegeln von Entzündungsmediatoren wie proinflammatorischen Zytokinen, Chemokinen und reaktiven Sauerstoffverbindungen sowohl im Hoden als auch im Ejakulat (Comhaire et al. 1980; Ludwig et al. 1998; Ochsendorf 1998; Hales et al. 1999). Desgleichen finden sich Veränderungen der sekretorischen Funktion der akzessorischen Geschlechtsdrüsen, erkennbar an der Veränderung von organspezifischen Ejakulatparametern wie z. B. den Enzymen $\gamma$-Glutamyltransferase, $\alpha$-Glukosidase, saurer Phosphatase, der Ejakulatfruktose und Spurenelementen (z.B. Zink) (Ludwig et al. 1998; Mahmoud et al. 1998; Vicari 1999). Im Gegensatz zu Entzündungsmediatoren haben diese Parameter aber scheinbar wenig Einfluss auf die Spermatozoenproduktion und -funktion, so dass sie mehr als diagnostische Kriterien zu verwenden sind, denn pathophysiologische Ansätze liefern (Depuydt et al. 1998; Trum et al. 1998). Der Nachweis eines kausalpathogenetischen Zusammenhanges zwischen Veränderungen dieser Parameter und Störungen der Spermatozo- enproduktion und -funktion konnte in zahlreichen Studien nicht eindeutig belegt werden (Ludwig et al. 1998).

Entzündungsmediatoren spielen hingegen eine wichtige Rolle für die Funktion spezifischer reproduktiver Gewebe unter physiologischen wie pathophysiologischen Bedingungen ( $\mathrm{Ha}-$ les et al. 1999). Unter physiologischen Bedingungen scheinen vor allem Wachstumsfaktoren und Zytokine für die Regulation der Steroidbiosynthese und Spermatogenese sowie "Crosstalk“ zwischen verschiedenen Zellpopulationen des Hodens verantwortlich zu sein (Hales et al. 1999). Unter pathophysiologischen Bedingungen sind die gleichen Faktoren für eine Reihe von Vorgängen verantwortlich, welche maßgeblich die Pathologie und den Verlauf der infektiösen Erkrankung bestimmen. Mit Fortschritten in der Molekularbiologie einhergehend sind hier spezifische Auswirkungen auf Gene aufgezeigt worden, welche für die Reproduktionsfunktion eine entscheidene Rolle spielen (Hales et al. 1999).

Pathogene Erreger als Ursache von urogenitalen Infektionen beeinflussen direkt reproduktive Gewebe, insbesondere Spermatozoen. Zahlreiche Studien haben auf diesem Umstand hingewiesen, wobei es sich hierbei zumeist um In-vitro-Studien handelt (Diemer et al. 1996; Huwe et al. 1998). Ob Erreger in vivo signifikant die reproduktive Kapazität beeinflussen können ist unklar, auch wenn in infizierten Ejakulaten direkte Interaktionen nachgewiesen werden können.

Die Produktion, Reifung und der Transport von Spermatozoen kann infolge unterschiedlicher Infektionen auf verschiedenen Ebenen des Urogenitaltraktes beeinflusst werden. Zahlreiche klinische Studien haben die Auswirkungen von Infektionen auf Ejakulatparameter beschrieben oder solche negiert (Kohn et al. 1998; Ludwig et al. 1998; Menkveld u. Kruger 1998). Unterschiedliche Studien zur Wirkung von urogenitalen Infektionen auf die männliche Fertilität weisen allerdings ein wesentliches Problem auf, welches in der teils erheblich differenten Klassifikation und Diagnostik von urogenitalen Infektionen begründet liegt. Neuere, internationale Klassifikationen und diagnostische Standards, wie z.B. die NIH-Klassifikation des Prostatitissyndromes werden 
hier hilfreich sein, um vergleichbare und vielleicht kongruentere Studien zu produzieren (Schaeffer 1998; Schaeffer 1999; Weidner et al. 1999).

Diese Review soll den Zusammenhang zwischen verschiedenen Infektionsformen und Fertilitätsstörungen des Mannes aufzeigen und wird neueste pathophysiologische Trends und Mechanismen ansprechen. Neben der Beschreibung unterschiedlicher urogenitaler Infektionen und deren aktueller Klassifizierung werden Wirkungen von pathogenen Erregern auf die Spermatozoen (Huwe et al. 1998) sowie die Rolle der Entzündungsmediatoren im Hoden und im Ejakulat in separaten Sektionen angesprochen.

\section{Klassifikation urogenitaler Infektionen und Assoziationen zu Fertilitätsstörungen}

Vereinfachend können urogenitale Infektionen in Urethritis, Prostatitis, „Samenwegsinfektion" und Epididymitis/ Epididymoorchitis unterteilt werden. Die folgenden Paragraphen widmen sich den Klassifikationskriterien, möglichen Pathomechanismen mit konsekutiver Beeinflussung der Fertilität sowie aktuellen "Evidence-based-Daten“ zur Beeinträchtigung von Parametern männlicher Fertilität.

\section{Urethritis}

Die infektiöse, sexuell erworbene Urethritis wird überwiegend von den Erregern Chlamydia trachomatis, Ureaplasma urealyticum und Neisseria gonorrhoeae verursacht (Schiefer 1998). Pathognomonisch für die akute Urethritis ist der Fluor urethralis. Die zytologische Diagnose basiert auf der Analyse von Harnröhrenabstrich und Ersturin. Nach dem Gießener Protokoll gelten $\geq 4$ Granulozyten/Gesichtsfeld (1.0oomal) im Harnröhrenabstrich oder $\geq 15$ Granulozyten/Gesichtsfeld im Sediment des Ersturins als beweisend für eine Urethritis (Schiefer 1998). Die ätiologische Klassifikation basiert auf folgenden 2 Kriterien:

1. Nachweis von Chlamydia trachomatis, Neisseria gonorrhoeae oder Trichomonas vaginalis,

2. hohe Konzentrationen von Harnwegsinfektserregern, Candida spe-

Tabelle 1

Klassifikation des Prostatitissyndroms gemäß NIH

\begin{tabular}{|c|c|c|}
\hline Kategorie & Name & Beschreibung \\
\hline 1 & Akute bakterielle Prostatitis & Akute Infektion der Prostata \\
\hline II & Chronische bakterielle Prostatitis & Rezidivierende Infektion der Prostata \\
\hline III & $\begin{array}{l}\text { Chronische abakterielle Prostati- } \\
\text { tis/chronisches Beckenschmerz- } \\
\text { syndrom }\end{array}$ & Keine nachweisbare Infektion \\
\hline IIIA & $\begin{array}{l}\text { Entzündliches chronisches } \\
\text { Beckenschmerzsyndrom }\end{array}$ & $\begin{array}{l}\text { Leukozyten in Ejakulat, Prostatasekret oder } \\
\text { Urin nach Prostatamassage }\end{array}$ \\
\hline IIIB & $\begin{array}{l}\text { Nichtentzündliches chronisches } \\
\text { Beckenschmerzsyndrom }\end{array}$ & $\begin{array}{l}\text { Keine Leukozyten in Ejakulat, Prostata- } \\
\text { sekret oder Urin nach Prostatamassage }\end{array}$ \\
\hline IV & $\begin{array}{l}\text { Asymptomatisches entzündliche } \\
\text { Prostatitis }\end{array}$ & $\begin{array}{l}\text { Keine subjektiven Symptome, entdeckt } \\
\text { durch Prostatabiopsie oder durch Leukozy- } \\
\text { ten in Prostatasekret oder Ejakulat im Zuge } \\
\text { einer Diagnostik aus anderen Gründen }\end{array}$ \\
\hline
\end{tabular}

zies, Mykoplasma species, d.h. $\geq 10^{4}$ $\mathrm{KbE} / \mathrm{ml}$ im Fluor oder $\geq 10^{3} \mathrm{KbE} / \mathrm{ml}$ im Ersturin.

\section{Urethritis und Fertilitätsstörungen}

Mögliche Auswirkungen auf die Fertilität ergeben sich aus potentieller Aszension der Infektion (Epididymoorchitis), Entwicklung einer chronischen Urethritis mit oder ohne Persistenz der ätiologisch verantwortlichen Erreger (Krieger et al. 1988) sowie der Entwicklung von Harnröhrenstrikturen oder Läsionen der hinteren Harnröhre in Höhe des Colliculus seminalis mit der Folge gestörter Ejakulation, wobei letztere Pathomechanismen nur in Einzelfällen beobachtet wurden. Bei der akuten Urethritis wird die Ejakulatanalyse aufgrund des entzündlichen Fluors und der dadurch bedingten Beeinträchtigung der Ejakulatanalyse nicht als sinnvoll angesehen.

\section{Prostatitissyndrom}

Bis vor kurzem wurde das Prostatitissyndrom in die akute bakterielle Prostatitis (ABP), die chronische bakterielle Prostatitis (CBP), die abakterielle Prostatitis (NBP) sowie die Prostatatodynie unterteilt. Die Schwierigkeit, klinisch zwischen abakterieller Prostatitis und Prostatodynie unterscheiden zu können, und die Tatsache, dass Patienten mit „abakterieller Prostatitis“ alle Kennzeichen eines chronischen
Schmerzsyndroms aufweisen, führte zu einem neuen Klassifizierungs- und Nomenklatursystem, welches durch das „National Institute of Health“ (NIH) der USA eingeführt wurde und die alte Nomenklatur in der internationalen wissenschaftlichen Literatur verdrängt hat (Nickel 1998) (Tabelle 1).

Das zentrale Entscheidungskriterium in der Differentialdiagnose zwischen entzündlichen Prostatitisformen einerseits und dem chronischen Beckenschmerzsyndrom andererseits ist der Nachweis entzündlichen Prostatasekrets. Dabei stehen prinzipiell zwei Methoden zur Verfügung, die eine gute Korrelation hinsichtlich ihrer Ergebnisse zeigen (Ludwig et al. 2000):

- Direktanalyse der Leukozyten im Prostatasekrettropfen nach Prostatamassage und

- Gewinnung von Exprimatharn zum Leukozytennachweis.

\section{Rationale Diagnostik beim Prostatitissyndrom}

Letztgenannte Technik macht sich zu Nutze, dass Prostatasekret, welches nach der Prostatamassage in der hinteren Harnröhre verbleibt, mit der letzten Urinportion noch ausgewaschen wird. Leukozytenfreier Erst- und Mittelstrahlurin vorausgesetzt, können nach Zentrifugation die Urinfraktionen in definierter Vergrößerung miteinander 


\section{Urologie}

Tabelle 2

Leukozytennachweis und Prostatitisdiagnose

\begin{tabular}{lll} 
Material & Parameter & Pathologischer Wert \\
\hline Exprimaturin & $\begin{array}{l}\text { Leukozyten/Gesichtsfeld } \\
400 \times \text { Vergrößerung } \\
\text { Leukozyten } / \text { Gesichtsfeld } \\
\text { Sekrettropfen (Exprimat) }\end{array}$ & $\geq 10$ \\
& $1000 \times$ Vergrößerung & $\geq 10$
\end{tabular}

verglichen werden. Die Grenzwerte sind in Tabelle 2 dargestellt.

Als ätiologisch relevante Erreger sind bei akuter und chronischer bakterieller Prostatitis gramnegative Erreger, insbesondere E. coli, aber auch grampositive Enterokokken akzeptiert. Chlamydia trachomatis und Ureaplasma urealyticum werden als ätiologisches Agens diskrepant diskutiert (Weidner et al. 1991). Nur in Einzelfällen gelten Anaerobier, Neisseria gonorrhoeae, Trichomonas vaginalis, Viren und Pilzspezies als klinisch relevant. Staphylokokkus saprophyticus ist als ätiologisches Agens umstritten, Mycobacterium tuberculosis kann im Rahmen einer Urogenitaltuberkulose eine spezifische Prostatitis verursachen. Als Methode der Wahl zur Infektionsdiagnostik dient die „4-Gläser-Probe“ (Meares u. Stamey 1968). Ihr Prinzip beruht auf der vergleichenden quantifizierenden Untersuchung gleicher Urinportionen vor und nach Prostatamassage; zweckmäßigerweise wird sie zusammen mit der Leukozytenanalyse durchgeführt. Mit dieser Methode lässt sich die chronische bakterielle Prostatitis durch quantifizierbare uropathogene Erreger diagnostizieren. In der häufigsten Konstellation finden sich Erregerzahlen (in KbE/ $\mathrm{ml}$ ) von $<10^{3}$ in Erst- und Mittelstrahlurin, $\geq 10^{4}$ im Prostataexprimat, sowie $\geq 10^{3}$ im Exprimaturin. Entscheidendes Kriterium ist jedoch eine 10fach höhere Erregerkonzentration im Exprimaturin verglichen mit Erst- und Mittelstrahlurin.

Im Gegensatz zu entzündlichen Formen des Prostatitissyndroms ist das nichtentzündliche „Chronic-pelvicpain-Syndrom" (Prostatodynie) durch das Fehlen von Entzündungszellen bei fehlendem Erregernachweis charakterisiert.

\section{Prostatitissyndrom und Fertilitätsstörungen}

Direkter Erregereinfluss - Bei der chronischen bakteriellen Prostatitis ist in $50 \%$ auch eine signifikante Bakteriospermie ( $\left.\geq 10^{3} \mathrm{KbE} / \mathrm{ml}\right)$ mit dem gleichen Erreger zu finden (Weidner et al. 1991; Weidner et al. 1999). Analog wird vermutet, dass auch hohe Konzentrationen $\left(\geq 10^{3} \mathrm{KbE} / \mathrm{ml}\right)$ von Ureaplasma urealyticum im Ejakulat ätiologisch relevant sind (Weidner et al. 1985). Weiter unten soll auf spezifische, direkte Interaktionen zwischen Erregerspezies und Spermatozoen im Detail eingegangen werden.

Entzündlich induzierte Autoimmunmechanismen, welche die Spermatogenese hemmen oder die Spermatozoenfunktion beeinträchtigen • Bei Patienten mit Schädigung der Blut-Hoden-Schranke durch genitale Infektion oder Obstruktion der ableitenden Samenwege sollen immobilisierende und agglutinierende Spermatozoenantikörper im Serum gehäuft auftreten. Durch Kontakt von Plasmaproteinen mit Tubuli seminiferi soll eine Extravasation von Spermatozoenantigenen mit Stimulierung immunkompetenter Zellen des lymphatischen Systems stattfinden. Ob Auftreten und Titerhöhe von Spermatozoenantikörpern einen Einfluss auf die Fertilität haben, ist trotz zahlreicher Studien umstritten. Im Einzelnen erlauben die vorliegenden Untersuchungen $\mathrm{zu}$ diesem Problem bei Epididymitis (Ingerslev et al. 1986) und Prostatitis (Jarow et al. 1990) zwar den Schluss, dass Spermatozoenantikörper vermehrt vorkommen, ihre Relevanz bleibt jedoch unklar. Neue Untersuchungen zum Auftreten von Antikörpern im Ejakulat unter Verwendung des Immunobeadtests (Jarow u. Sanzone 1992) weisen darauf hin, dass wahrscheinlich nur eine Vasektomie ein echtes Risiko zur Antikörperproduktion darstellt. Auftretende Antikörper im Sinne eines Antibody-coating (Weidner et al. 1991) sind diagnostisch in Einzelfällen relevant, nicht jedoch für die Routinediagnostik einzusetzen.

Indirekte Beeinträchtigung der Spermatozoenfunktion durch Induktion einer sekretorischen Dysfunktion - Eine Veränderung der das Ejakulat bildenden Drüsensekrete ist bei der männlichen Adnexitis vor allem bei der Prostatovesikulitis bekannt (Weidner et al. 1999). Herabgesetzt sind Fruktose, Zitronensäure, saure Phosphatase, Kationen (Zink, Magnesium, Kalzium) sowie der zinkhaltige "prostatische antibakterielle Faktor" (PAF). Vermehrt nachweisbar dagegen sind, neben Coeruloplasmin und Complement $\mathrm{C}_{3}$, gegen die ätiologisch verantwortlichen Erreger gerichtete spezifische Antikörper, welche über Serumdiffusion das Ejakulat erreichen. Ebenfalls wird lokal gebildetes sekretorisches IgA gefunden. Inwieweit diese bei der chronisch bakteriellen Prostatitis bewiesenen Veränderungen auch für die chlamydien- und ureaplasmenassoziierte „abakterielle Prostatitis“ zutreffen, wird diskrepant diskutiert. Gesichert scheint zumindest eine reduzierte Zinkkonzentration, wobei Zink in der Zellkultur einen bakteriziden Effekt gegen Chlamydien, nicht jedoch gegen Ureaplasmen besitzt.

Induktion einer leukozytären Reaktion im Ejakulat - Die klinische Bedeutung erhöhter Leukozytenzahlen im Ejakulat wird insbesondere als Ursache männlicher Subfertilität kontrovers diskutiert (Aitken u. Baker 1995). Es scheint akzeptiert, dass nur erhöhte Zahlen von Leukozyten, insbesondere neutrophile Granulozyten, sowie ihre Produkte im Seminalplasma (z.B. Elastase) eine Entzündung der männlichen Adnexe anzeigen. Unsere Arbeitsgruppe konnte bei chronischer Prostatitis signifikant erhöhte Elastase im Seminalplasma nachweisen mit einem Grenzwert von 600 $\mathrm{ng} / \mathrm{ml}$ (Ludwig et al. 1998). Die Klassifikation leukozytärer Subtypen, z.B. durch monoklonale Antikörper, scheint dabei für diagnostische Zwecke keine Rolle zu spielen (Eggert-Kruse et al. 1992). Der von der WHO empfohlene 
Tabelle 3

Einfluß der „chronischen Prostatitis“ auf Spermatozoendichte, -motilität und -morphologie

\begin{tabular}{lllll} 
Studie & \multicolumn{2}{l}{ Negativer Einfluß auf: } & $\begin{array}{l}\text { Diagnose } \\
\text { korrekt? }\end{array}$ \\
\cline { 2 - 4 } & Dichte & Motilität & Morphologie & \\
\hline Caldamone et al. 1984 & n.u. & + & n.u. & - \\
Giamarellou et al. 1984 & + & + & $(+)$ & + \\
Christiansen et al. 1991 & + & + & + & - \\
Weidner et al. 1991 & - & - & - & + \\
Leib et al. 1994 & - & + & + & - \\
Krieger et al. 1996 & - & + & - & + \\
Huaijin et al. 1998 & + & n.u. & n.u. & + \\
& & & &
\end{tabular}

Richtwert einer signifikanten Leukozytospermie liegt bei $\geq 1$ Million Leukozyten/ml Ejakulat (WHO 1992). Betont werden sollte, dass eine Leukozytospermie zwar auf einen entzündlichen Prozess hinweist, keinesfalls aber einen beweisenden Charakter hat. Eine Leukozytospermie kann auch sekundärer Ausdruck einer Immunreaktion sein. Eine nichtentzündlich bedingte Leukozytospermie ist auch als Antwort auf Zelldetritus denkbar, die als Folge abnormaler Spermatozoenproduktion oder-degeneration entstehen. Bisherige Studien konnten erhöhte Leukozytenzahlen im Ejakulat bei der chronischen Prostatitis im Vergleich zur Prostatodynie oder gesunden Kontrollen nachweisen (Weidner et al. 1991; Krieger et al. 1996). Die mit einer Leukozytospermie assoziierte erhöhte Ausschüttung von Leukozytenprodukten wie Zytokinen und reaktiven Sauerstoffverbindungen wird an anderer Stelle erörtert.

Prostatitissyndrom und Ejakulatparameter - Seit Jahren wird ein negativer Effekt der chronischen Prostatitis auf Spermatozoendichte, -motilität und -morphologie diskutiert (Caldamone u. Cockett 1978; Weidner et al. 1991; Weidner et al. 1999). Oft wurde die chronische Prostatitis mit dem Nachweis von Mikroorganismen und Leukozytospermie assoziiert und hierdurch eine Beeinflussung dieser Spermiogrammparameter erklärt. Leider wurden bis in die 90 er Jahre bei einem Teil der Studien, die sich mit der Auswirkung der chronischen Prostatitis auf Fertilitätsparameter im Spermiogramm bezogen, nicht die allgemein akzeptierten Diagnosekriterien
(Drach et al. 1978; Nickel 1998) zugrunde gelegt. Aber auch die Studien, welche diese essentiellen Kriterien beachten, machen aufgrund widersprüchlicher Ergebnisse eine definitive Beurteilung dieser Frage schwierig. Eine Übersicht über die aktuelle Literatur gibt Tabelle 3 . Ein eindeutiger Hinweis darauf, dass die chronische Prostatitis einen negativen Effekt auf die Ejakulatqualität besitzt, wäre der positive Effekt einer antibiotischen Therapie. Leider sind die verfügbaren Studien entweder nicht kontrolliert (Giamarellou et al. 1984) oder konzentrieren sich auf die Reduktion einer Leukozytospermie, wobei aufgrund der hohen spontanen Resolutionsate der Leukozytospermie dieses als Therapieziel ungeeignet scheint. In Einzelfällen können prostatitische Symptome mit einem hohen Samenwegsverschluss (Utrikuluscyste) assoziiert sein, wobei die operative Therapie (transurethrale Resektion des Ductus ejaculatorius TURED) nicht nur zu einer Besserung der Schmerzsymptomatik, sondern auch zu einer Verbesserung der Ejakulatqualität führen soll (Dik et al. 1996).

\section{Epididymitis/Epididymoorchitis}

Die Diagnose der Epididymitis wird klinisch gestellt: Schwellung, Schmerz und Induration des Nebenhodens sind richtungsweisend. Der Hoden kann im Sinne einer Epididymoorchitis betroffen sein. Bei sexuell aktiven jungen Männern unter 35 Jahren entsteht die Epididymitis am häufigsten infolge einer Urethritis durch sexuell übertragbare Erreger. Bei älteren Männern überwiegen ätiologisch Erreger von Harnwegs- infektionen, wobei subvesikale Obstruktion, anatomische Anomalien und instrumentelle Manipulationen am Urogenitaltrakt die wichtigsten kausalpathogenetischen Faktoren darstellen. Spezifische (Epididymo-)orchitiden bei Tuberkulose, Lues und Brucellose, sowie virale Orchitiden müssen differentialdiagnostisch abgegrenzt werden. Die Ejakulatanalyse, insbesondere die Leukozytenanalyse, kann eine persistierende entzündliche Aktivität anzeigen. Bei der chronischen Epididymitis sollen Makrophagen im Ejakulat vermehrt zu finden sein (Haidl 1990).

\section{Epididymoorchitis und Fertilität}

Bei akuter Epididymitis liegt in zwei Drittel der Fälle eine Spermatogenesestörung auf dem Boden einer Begleitorchitis vor, die sich klinisch in einem intermittierenden OAT-Syndrom äußert. Die Frage, warum der unbeteiligte kontralaterale Hoden-Nebenhoden-Komplex diese Spermiogrammveränderungen nicht kompensiert, kann nicht abschließend beantwortet werden. Diskutiert werden direkt entzündlich wirkende, toxische und autoallergische Mechanismen, in Einzelfällen aber auch eine subklinische Orchitis des kontralateralen Hodens (Osegbe 1991). Allerdings soll eine frühzeitige Antibiotikatherapie diesen Veränderungen entgegenwirken (Weidner et al. 1990). Wichtig erscheint, dass sich unter initialer antimikrobieller Therapie die Spermatogenese innerhalb von 6-12 Wochen regeneriert (Weidner et al. 1990). Isolierte Motilitätsstörungen werden agglutunierenden und immobilisierenden Effekten von Mikroorganismen zugeschrieben. Einige Autoren beschreiben bei der Orchitis auch entzündungstypische Störungen der Spermatozoenmorphologie (Hofmann u. Haider 1985). Hier sollen Überstreckungs- und akrosomale Formanomalien kennzeichnend sein. Weiterhin soll in Einzelfällen durch eine entzündliche Destruktion von Samenkanälchen noch nach Jahren ein kompletter Verlust der Spermatogenese, d.h. eine testikuläre Azoospermie resultieren. Davon abzugrenzen ist die selten bei der Epididymoorchitis auftretende entzündliche Hodennekrose. Die postepididymale Obstruktion mit konsekutiver Azoospermie ist bekannte Folge einer beidseitigen Epididymitis. In der 


\section{Urologie}

Vergangenheit sollen 40-50\% der Fälle von obstruktiver Azoospermie postinfektiöser Genese gewesen sein (Weidner et al. 1990).

\section{Samenwegsinfektion (male accessory sex gland infection - MAGI)}

Die Definition dieses Krankheitsbildes ist heterogen. Zumeist versteht man darunter eine klinisch stumme, chronisch-aszendierende Infektion der männlichen Adnexe insgesamt. Das Fehlen subjektiver Symptome und die unsichere Zuordnung objektiver Zeichen und Befunde machen gegenwärtig nicht nur eine definitive Einordnung als Krankheitsbild unmöglich, sondern lassen daher auch die Frage offen, ob es sich hier überhaupt um ein eigenständiges Krankheitsbild handelt. Gemäß WHO wird eine Samenwegsentzündung bei einer signifikanten Leukozytospermie, d. h. $\geq 10^{6}$ Leukozyten $/ \mathrm{ml}$ Ejakulat, definiert (WHO 1993). Erst dann wird das Anlegen einer Ejakulatkultur empfohlen. Von einer signifikanten Bakteriospermie wird bei $\geq 10^{3} \mathrm{KbE} / \mathrm{ml} \mathrm{Eja-}$ kulat Harnwegsinfektserreger gesprochen. Als pathogen gilt ebenfalls der Nachweis von C. trachomatis, Mykoplasmen und Mycobacterium tuberculosis. Vor dem Hintergrund, dass in der Mehrzahl der Fälle ursächlich eine sexuell übertragene Infektion vermutet wird, die von vornherein asymptoma- tisch oder kurzfristig oligosymptomatisch verlaufen ist, entwickelte die WHO ein Diagnosesystem, das anhand einer Kombination möglicher Veränderungen versucht, diesen Begriff näher einzugrenzen (WHO 1993) (Tabelle 4). Trotz dieses Ansatzes einer Objektivierung und Einordnung bleibt die Definition einer "male accessory gland infection" unscharf.

\section{Wirkung pathogener Erreger von Genitalinfektionen auf Spermatozoen}

Ejakulatinfektionen können einen Einfluss besonders auf die Motilitätsparameter und die Morphologie von Spermatozoen haben. Die diesbezüglich am intensivsten untersuchten Erreger sind E. coli, Mykoplasma spezies, Ureaplasma urealyticum, und Chlamydia trachomatis. Neben diesen Keimen werden in der Literatur für fast alle weiteren uropathogenen Erreger kontroverse Ergebnisse in vitro und in vivo diskutiert. Als Ursachen für die Motilitätshemmung der Spermatozoen unterscheidet man zwischen primären und sekundären Pathomechanismen. Die primären Pathomechanismen sind die der Adhäsion, Agglutination, morphologische Veränderungen der Spermatozoen und potentielle Toxinfreisetzung. Als sekundäre Pathomechanismen werden die Leukozytenwirkung, Spermatozoenan-

Tabelle 4

Kriterien zur Definition einer „male accessory gland infection“ (MAGI) (WHO 1993)

A Anamnese und
körperliche Zeichen

B

Prostatasekret

C Ejakulatveränderungen

Beweisende Kombinationen
Anamnese einer Harnwegsinfektion und/oder Epididymitis und/oder sexuell übertragbare Erkrankung und/oder verdickter oder schmerzhafter Nebenhoden und/oder verdickter Ductus deferens und/oder pathologische digitorektale Untersuchung

Pathologisches Prostatasekret und/oder Urin nach Prostatamassage

$110^{6}$ Leukozyten/ml

2 Ejakulatkultur mit signifikantem Wachstum pathogener Keime

3 pathologisches Aussehen und/oder Viskosität und/ oder pH und/oder Biochemie des Seminalplasmas

Ein Zeichen aus $A+$ ein Zeichen aus $B$ ein Zeichen aus $A+$ ein Zeichen aus $C$ ein Zeichen aus $B+$ ein Zeichen aus $C$ 2 Zeichen aus $C$ in jedem Ejakulat tikörper und reaktive Sauerstoffverbindungen (ROS) diskutiert. Im Folgenden werden die primären Pathomechanismen der genannten Erreger und ihr Einfluss auf die Spermatozoen unter besonderer Berücksichtigung der Spermatozoenmotilität dargestellt werden.

\section{Escherichia coli}

Erstmals wurde der motilitätshemmende Einfluss von E. coli auf humane Spermatozoen in vitro von Schirren u. Zander beschrieben (1966). Es wurden hohe Konzentrationen von $10^{8}$ Keimen/ $\mathrm{ml}$ verwendet. Ebenfalls beschrieben Teague et al. eine Motilitätsminderung in vitro und beobachteten dabei Spermatozoenagglutinationen (Teague et al. 1971). Dies war zudem an isolierten E. coli aus Urin und Zervikalschleim zu reproduzieren, E. coli-Endotoxin hatte jedoch keinen Effekt auf die Spermatozoenmotilität. Die Wirkung von E. coli wurde in Folge immer wieder kontrovers diskutiert. Von einigen Autoren wurde der motilitätshemmende Effekt von E. coli bestätigt (del Porto et al. 1975; Paulson und Polakoski 1977; Auroux et al. 1991; Wolff et al. 1993; Diemer et al. 1996) bzw. in Frage gestellt (Appell und Evans 1978; Makler et al. 1981). Wolff et al. fanden heraus, dass Agglutinationsphänome durch Mannose blokkiert werden konnten (Wolff et al. 1993). Diemer et al. konnten erstmals in in vitro Versuchen ein genaues Bakterien/Spermatozoenverhältnis angeben, bei dem eine Immobilisation der Spermatozoen zu beobachten war (Diemer et al. 1996). In elektronenmikroskopischen Untersuchungen konnte diese Arbeitsgruppe als weitere Ursache der Immobilisierung neben Adhäsion und Agglutination ultrastrukturelle Schädigungen der Spermatozoen, insbesondere die Ablösung des Akrosoms und Schwellung des Mittelstückes mit anschließender Invagination der Geißel, nachweisen (Diemer et al. 1996). Sanchez et al. konnten verschiedene Adhäsionsmechanismen von E. coli mittels Fimbrienreaktionen (Typ 1 und Typ 2) elektronenmikroskopisch nachweisen, die nach Migration durch Zervikalschleim noch vorhanden waren und die eine morphologische Erklärung für die Verschleppung von Samenwegsinfektionen in den weiblichen Genitaltrakt sein könnten und dort Entzündungen 
verursachen, die ggf. eine Sterilität zur Folge haben (Sanchez et al. 1989). Zusätzlich untersuchten andere Arbeitsgruppen mit verschiedenen Tests die Penetrationsfähigkeit von Spermatozoen im Zervikalschleim unter dem Einfluss von E. coli. Die Vergleichbarkeit der verschiedenen Studien wird jedoch durch unterschiedliche Versuchsansätze sowie die Verwendung unterschiedlicher Serotypen erschwert.

\section{Ureaplasma urealyticum}

Seit Anfang der 70 er Jahre beschäftigten sich vermehrt Arbeitsgruppen mit der Wirkung von Ureaplasma urealyticum auf die Spermatozoenmotilität, nachdem ihre Bedeutung bei der chronischen abakteriellen Prostatitis von Gnarpe und Friberg beschrieben wurde (Gnarpe u. Friberg 1972). Eine Reihe von klinischen und experimentellen (Hofstetter et al. 1978; Chang et al. 1984; Nunez-Calonge et al. 1998) Studien konnten eine Beeinflussung der Motilität humaner Spermatozoen oder deren Bewegungsparameter darlegen. Keine Veränderungen der Ejakulatparameter bei Ureaplasmennachweis fanden die Arbeitsgruppen von Desai et al. (Desai et al. 1980), Cintron et al. (Cintron et al. 1981) und Hargreave et al. (Hargreave et al. 1982). Bei einer erfolgreichen antibiotischen Therapie von Patienten mit positiver Ureaplasmenkultur konnten Swenson et al. (Swenson et al. 1979) eine verbesserte Motilitätsrate registrieren. Xu et al. wiesen eine Verminderung der Befruchtungsfähigkeit in vitro nach, da sie im Tiermodell die Verminderung der Spermatogenese und ebenso morphologische Veränderungen in den Tubuli seminiferi feststellten (Xu et al. 1997). Verschiedene Autoren charakterisierten die morphologischen Veränderungen der Spermatozoen bei Ureaplasmennachweis (Fowlkes et al. 1975; $\mathrm{Xu}$ et al. 1997; Nunez-Calonge et al. 1998). Insbesondere werden diese Veränderungen durch Adhäsionen an Kopf und Geißeln sowie eine spiralige Aufdrehung derselben erklärt. Grossgebauer et al. konnten elektronenmikroskopisch bei massiv mykoplasmenkontaminierten Nativejakulaten infertiler Männer spiralig geformte und am Halsabschnitt knotig aufgetriebene Spermatozoen nachweisen (Grossgebauer et al. 1977).

\section{Chlamydia trachomatis}

Für Chlamydia trachomatis ist ebenfalls ein motilitätsmindernder Effekt und die Adhäsion an Spermatozoen gezeigt worden (Mardh et al. 1978). EggertKruse et al. sahen die Hauptbedeutung der Chlamydienbesiedelung des Ejakulates in deren Verschleppung in den oberen weiblichen Genitaltrakt mit anschließender Adnexinfektion und späterer entzündlich bedingter tubarer Sterilität bzw. Erregerpersistenz (EggertKruse et al. 1990; Eggert-Kruse et al. 1998). Ferner begünstigt eine subklinische Infektion mit Chlamydia trachomatis eine Immunreaktion auf Spermatozoen (Witkin et al. 1993). Eine ähnliche Immunantwort kann im weiblichen Genitaltrakt mit der Bildung von Spermatozoenantikörpern erfolgen (Witkin et al. 1993). Infertilität solcher chlamydieninfizierter Paare resultiert aus einer direkten entzündlichen Immunantwort in der Zervix oder dem Endometrium bei wiederholter Chlamydienexposition im Sinne einer "Ping-Pong-Infektion“ (Witkin et al. 1993). Soffer et al. haben bei positivem Nachweis von Chlamydia trachomatis im Ejakulat infertiler Männer gleichzeitig Spermatozoenantikörper gefunden (Soffer et al. 1990). Eine neuere Arbeit von Levy et al. konnte jedoch zeigen, dass keine Korrelation zwischen einer positiven Chlamydia-trachomatis-Kultur und dem Nachweis von Spermatozoenantikörpern bestand (Levy et al. 1999). Soffer et al. und Levy et al. fanden Spermatozoenantikörper ebenfalls bei Infektionen mit Ureaplasma urealyticum (Soffer et al. 1990; Levy et al. 1999).

\section{Enterokokken}

Schirren $u$. Zander führten erstmals Inkubationsversuche mit einem $\beta$-hämolysierenden Streptokokkenstamm durch, der jedoch keinen Einfluss auf die Motilität hatte (Schirren und Zander 1966). Bisson u. Czyglick hingegen hatten in in vitro Versuchen mit hohen Konzentrationen von Streptococcus faecalis eine deutliche Motilitätsabnahme beobachtet (Bisson u. Czyglik 1974). Ferner fanden sie, dass der Prozentsatz an eingerollten Spermatozoengeißeln proportional zur hinzugefügten Bakterienkonzentration anstieg. Makler führte einen In-vitro-Inkubationsversuch mit verschiedenen Erregern, unter anderem Enterokokken, in einer Bakterienkonzentration von $10^{7} \mathrm{Keime} / \mathrm{ml}$ direkt nach Beimpfen des Ejakulates und 2 Stunden nach Inkubation desselben bei $37^{\circ} \mathrm{C}$ durch (Makler et al. 1981). Als Kontrolle diente eine Probe mit zusätzlicher Antibiotikagabe zur Bakterienhemmung. Dabei konnte kein motilitätshemmender Effekt beobachtet werden. Dies unterstützt auch die von Huwe et al. gezeigten In-vitro-Ergebnisse, welche zeigten, dass Enterokokken keinen Einfluss auf die Spermatozoenmotilität haben (Huwe et al. 1998). Es gibt noch zahlreiche In-vivo-Untersuchungen von Ejakulaten, die eine häufige Besiedelung mit Enterokokken nachweisen (Stone et al. 1986; Jacques et al. 1990). Andere Arbeitsgruppen konnten keinen signifikanten Unterschied in der Eindringtiefe von Spermatozoen in mit Enterokokken kontaminiertem bovinen Mukus im modifizierten Kapillarpenetrationstest nach Kremer im Vergleich mit sterilem Mukus finden. Alle beschriebenen Studien, mit Außnahme der von Bisson u. Czyglick vorgelegten (Bisson u. Czyglik 1974), unterstützen die Auffassung, dass Enterokokken keinen Einfluss auf die Motilitätsparameter haben und somit für die Fertilität von untergeordneter Bedeutung sind.

\section{Pseudomonas aeruginosa}

Pseudomonas aeruginosa gilt als häufiger Erreger der akuten und chronischen Prostatitis sowie als unspezifischer Erreger bei der Epididymitis und Orchitis (Schiefer et al. 1994; Schiefer 1998). In der Literatur wurde erstmals Anfang der 50 er Jahre in einer In-vitro-Studie über Pseudomonas aeruginosa berichtet. Hierbei wurden aus Zervicalschleim Erreger isoliert und anschließend in $v i$ tro mit Ejakulat versetzt und über mehrere Stunden bei $37^{\circ} \mathrm{C}$ Inkubation beobachtet. Dabei konnte kein Einfluss von Pseudomonas auf die Spermatozoenmotilität nachgewiesen werden. Ebenfalls wurden auch keine Agglutinationsphänomene beobachtet. Jaques et al. fanden in einer In-vivo-Studie keine Unterschiede in der Spermaqualität, insbesondere der Motilität, zwischen erregerpositiven und -negativen Ejakulatkulturen (Jacques et al. 1990). Darunter waren ebenfalls pseudomonaspositive Kulturen, die keinerlei Einfluss auf die 
Motilitätsparameter hatten. Es ist anzumerken, dass Pseudomonas bei dieser Studie nur in $0,8 \%$ der Fälle nachweisbar war.

Huwe et al. konnten den Einfluss auf die Motilität von humanen Spermatozoen nicht eindeutig klären. Es lässt sich aus diesen Experimenten zurückhaltend ableiten, dass ein Motilitätsverlust durch Pseudomonas aeruginosa in hohen Konzentrationen und nach einer Inkubationszeit von mehr als 6 Stunden auftreten kann (Huwe et al. 1998).

\section{Candida albicans}

Tuttle et al. beschrieben eine deutliche Abnahme der Spermatozoenmotilität, wenn frisches Ejakulat und Candida albicans koinkubiert wurden (Tuttle et al. 1977). Daraufhin führten sie Experimente mit aus Urinkulturen gewonnenen Candida albicans in Konzentrationen von $10^{2}-10^{7}$ Erregern $/ \mathrm{ml}$ durch. Gleich nach dem Ansetzen der Proben zeigte sich erst eine signifikante Motilitätsverminderung $\mathrm{ab} 10^{4}$ Candida/ml, die sich bei einer Konzentration von $10^{7}$ in einer völligen "Lokalbeweglichkeit“, nur mit Schwanzvibrationen, äußerte. Dies setzte sich in der Messung im Verlauf der Inkubation auch in den anderen niedrigeren Ausgangskonzentrationen fort. Huwe et al. konnten in In-vitro-Inkubationsversuchen den motilitätshemmenden Effekt von Candida albicans bestätigen (Huwe et al. 1998). Desweiteren konnten Tuttle et al. bei ihren Tests mit Candida albicans ein Phänomen der Spermatozoenagglutination bei Konzentrationen ab $10^{4}$ Errregern/ $\mathrm{ml}$ zuerst nach 2 Stunden und, noch deutlicher, nach 4 Stunden Inkubation beobachten (Tuttle et al. 1977). Sie stellten in den Proben mit $10^{6}$ und $10^{7}$ Candi$\mathrm{da} / \mathrm{ml}$ direkt nach Inkubation eine Art Ausflockung der Proben mit anschließender granulöser, visköser und klebriger Veränderung der Konsistenz der Speramatozoensuspension fest. In der Arbeit von Huwe et al. konnten die Beobachtungen von Tuttle et al. nicht bestätigt werden (Tuttle et al. 1977; Huwe et al. 1998). Während der gesamten Inkubationszeit konnten keine Agglutinationen oder Adhäsionen von Candida und Spermatozoen verzeichnet werden. Es schien vielmehr, dass die Candidapartikel aufgrund ihres deutlichen Größenunterschiedes gegenüber den Sper- matozoen ein mechanisches Hindernis darstellten. Dies würde die Beobachtung, dass gleich zu Beginn der Untersuchungen die Progressivmotilität deutlich in der hohen Konzentration von 20 Millionen/ml herabgesetzt war, nicht jedoch die Gesamtmotilität, erklären.

\section{Staphylococcus saprophyticus}

Dieser Erreger gehört zu der Standortflora des Urogenitaltraktes sowohl der Frau als auch des Mannes und wurde früher als apathogener Erreger angesehen. Heute weiß man, dass bei jungen Frauen dieser Keim in ca. 10-20\% für eine akute Harnwegsinfektion verantwortlich ist. Huwe et al. konnten nachweisen, dass Staphylococcus saprophyticus in hohen, nichtphysiologischen Konzentrationen keinen Einfluss auf die Motilitätsparameter humaner Spermatozoen hat (Huwe et al. 1998).

Zusammenfassend lässt sich sagen, dass der negative Einfluss von verschiedenen Erregern auf die Spermatozoenmotilität nicht einheitlich beurteilt werden kann, sondern unter Berücksichtigung der einzelnen Erregerspezies, deren Konzentrationen und des zeitlichen Einflusses derselben betrachtet werden muss.

\section{Entzündungsmediatoren: Basic Research und Klinik}

\section{Entzündungsmediatoren}

Neben pathogenen Erregern von urogenitalen Infektionen sind vor allem Entzündungsmediatoren für die Pathophysiologie einer Infektion verantwortlich (Hales et al. 1999). Der Begriff Entzündungsmediatoren umfasst verschiedene Klassen von Substanzen, welche von immunkompetenten Zellen oder von zellulären Elementen des Bindegewebes als Reaktion auf eine Erregerinvasion sezerniert werden. Entzündungsmediatoren verändern vielfältige Funktionen eines entzündeten Gewebes und zeichnen für die Kardinalsymptome einer Entzündung verantwortlich. Elemente der unspezifischen Immunabwehr wie Gewebsmakrophagen und segmentierte Granulozyten sezernieren nach Erregerkontakt reaktive Sauerstoffspezies zur Abtötung von pathogenen Bakterien (Ochsendorf 1998). Proinflammatorische Zytokine und Chemokine von
Gewebsmakrophagen aktivieren und dirigieren immunkompetente Zellen an den Ort des Entzündungsgeschehens und initiieren die spezifische Immunabwehr. Alle sezernierten Mediatoren üben aber nicht nur eine immunologische Funktion aus sondern haben pathophysiologische Wirkungen auf benachbarte Zellen und Gewebe (Hales et al. 1999; Jonsson et al. 1999). Im Rahmen urogenitaler Infektionen können dies Zellen des Hodens, Spermatozoen oder andere Gewebe akzessorischer Geschlechtsdrüsen sein (Depuydt et al. 1998; Hales et al. 1999). Nachfolgend sollen die Wirkungen der wichtigsten Entzündungsmediatoren auf spezifische, reproduktiv bedeutende Zellpopulationen dargestellt werden. Schwerpunkt der Darstellung wird dabei die Wirkung auf Leydig-Zellen, das Germinalepithel des Hodens sowie auf die Spermatozoenfunktion direkt sein.

\section{Zytokine}

Zytokine haben eine weite biologische Wirkungsbreite und sind nicht nur für die Koordination des Immunsystemes im Sinne von molekularen Effektoren und für die parakrine Signaltransduktion von Bedeutung. Zytokine sind eine nicht ganz exakt definierte Gruppe von Polypeptiden, welche von immunkompetenten Zellen sezerniert werden können (Hales et al. 1999). Darüber hinaus gibt es eindeutige Hinweise auf die Zytokinproduktion in immunologisch inaktiven Zellen, wo sie als intrazelluläre und parakrine „messenger" fungieren. Die Wichtigkeit dieser Funktion wird allerdings durch die Tatasache in Frage gestellt, dass z.B. Mäuse ohne funktionsfähigen IL-1-Rezeptor (IL-1-Rezeptor-,,Knock-out-Maus“) trotz allem fertil sind und keine Störungen der Spermatogenese aufweisen (Cohen und Pollard 1998).

Im Hoden haben Zytokine 2 wesentlich unterschiedene Funktionen: Zum einen erfüllen sie unter physiologischen Bedingungen die Funktion von Wachstums- und Differenzierungsfaktoren. Zum anderen üben sie als Effektoren im Rahmen inflammatorischer Reaktionen gezielte Wirkungen auf testikuläre Zellen aus. So werden z. B. in Leydig-Zellen des Hodens Gene für Enzyme und Faktoren der Steroidbiosynthese supprimiert, wodurch die Steroid- 
biosynthese temporär blockiert wird (Hales et al. 1999; Sam et al. 1999). Auch das Germinalepithel wird von $\mathrm{Zy}$ tokinen im Rahmen inflammatorischer Reaktionen beeinflusst. Chronische Applikation von Interferonen resultiert so z. B. in profunden Störungen der Spermatogenese (Bussiere et al. 1996).

Erhöhte Zytokinspiegel im Ejakulat sind Anzeichen einer Ejakulatinfektion (Depuydt et al. 1998; Denison et al. 1999). Darüber hinaus scheinen Zytokine gezielt Funktionen von Spermatozoen $\mathrm{zu}$ beeinflussen und liefern somit eine Basis für pathophysiologische Vorgänge im Infektionsgeschehen (Depuydt et al. 1998; Fujisawa et al. 1998).

Im Rahmen dieser Übersicht sollen vor allem pathophysiologische Wirkungen von Zytokinen dargestellt werden, welche im Rahmen urogenitaler Infektionen nachzuweisen sind. Die sehr komplexen Regulationsfunktionen von Zytokinen im Hoden finden sich an anderer Stelle beschrieben (Hales et al. 1999).

Tumornekrosefaktor $\alpha($ TNF $\alpha) \cdot$ Tumornekrosefaktor $\alpha$ ist ein 17 Kilodalton (kD) schweres, glykosiliertes Polypeptid, welches von aktivierten Makrophagen sezerniert wird. TNF $\alpha$ bindet als Trimer an TNF-Rezeptoren, welche sich auf nahezu allen Zellen des Körpers finden und stellt das erste Zytokin der proinflammatorischen Zytokinkaskade dar. Die Sekretion von Interleukinen (IL-1 und IL-6) wird durch TNF $\alpha$ induziert wobei TNF $\alpha$ insgesamt die Funktion eines Initiators der Immunreaktion übernimmt (Cerami 1992).

Im Hoden bewirkt die Sekretion von TNF $\alpha$ die gezielte Suppression von Steroidbiosyntheseenzymen in LeydigZellen, wobei diese Wirkung intrazellulär über Aktivitatsveränderungen der Transkriptionsfaktors AP-1 ausgeübt wird (Li et al. 1997; Hales et al. 1999).

TNF $\alpha$ findet sich ebenfalls in erhöhter Konzentration im Ejakulat im Falle einer Ejakulatinfektion. In vitro sind profunde Effekte von TNF $\alpha$ auf die Spermatozoenmotilität und die Fertilisationskapazität von Spermatozoen (zonafreier-Hamsterei-Penetrations-

test) nachgewiesen worden, ob in vivo erreichbare Konzentrationen dieses Zytokines aber den gleichen Effekt zeigen ist unklar (Hill und Anderson 1992; Depuydt et al. 1998).
Interleukine - Interleukine stellen eine Familie von Zytokinen mit zahlreichen Vertretern $(>18)$ dar. Interleukine werden im Rahmen der proinflammatorischen Zytokinkaskade von Makrophagen und Lymphozyten sezerniert, wobei ihre Auswirkungen in und ausserhalb des Immunsystemes vielfältig sind.

In Leydig-Zellen wird die Expression des Steroidbiosyntheseenzymes P450c17 durch Interleukin-1 (IL-1) und IL-2 downreguliert (Guo et al. 1990; Hales et al. 1999).

Interleukine im Ejakulat sind mit Fertilitatsstörungen assoziiert, und in vitro konnte ebenfalls eine Beinflussung der Spermatozoenmotilität gezeigt werden. Interleukin-8 wird gegenwärtig als signifikanter Marker für Ejakulatinfektionen diskutiert, eine Rolle für Spermatozoenfunktion und reproduktive Kapazität ist derzeit jedoch nocht nicht bekannt (Koumantakis et al. 1998). Weitere Studien werden hier die Korrelation mit anderen Entzündungsparametern untersuchen (Depuydt et al. 1998; Fujisawa et al. 1998).

Interferone (IFN) • Interferone repräsentieren eine Zytokinklasse aus strukturell und funktionell verwandten Polypeptiden mit 3 wesentlichen Gruppen:

- IFN $\alpha$,

- IFN $\beta$ und

- IFN $\gamma$.

Während IFN $\alpha$ und IFN $\gamma$ von immunkompetenten Zellen sezerniert werden, stammt IFN $\beta$ von Fibroblasten und Epithelzellen (Borden 1992).

Im Hoden werden Interferone von residenten testikulären Makrophagen sezerniert. Die Wirkungen auf testikuläre Zellen sind vielfältig. In Leydig-Zellen des Hodens konnte die Suppression von StAR (steroidogenic acute regulatory protein), welches für den mitochondrialen Cholesterinimport verantwortlich ist, sowie den Steroidbiosyntheseenzymen $\mathrm{P} 450$ scc (side chain cleavage) und $\mathrm{P} 450 \mathrm{c} 17$ auf transkriptioneller Ebene nachgewiesen werden (Hales et al. 1999).

INF $\gamma$ resultiert im Tierversuch nach chronischer Applikation in schweren Testosteronsynthese und Spermatogenesestörungen (Orava et al. 1986), während INF $\alpha$ die Spermatogenese stimulieren konnte (Hibi et al. 1997).
INF $\gamma$ wirkt dabei unter anderem über die Induktion von induzierbarer Nitritoxidsynthetase (iNOS) in Sertoli-Zellen, welches in hohen Nitritoxidspiegeln resultiert, die ihrerseits die Expression und Funktion von Genen beeinflussen können (Hales et al. 1999).

Interferone haben einen negativen Einfluss auf die Spermatozoenmotilität und die Akrosomenfunktion, und erhöhte Spiegel von IFN $\alpha$ und IFN $\gamma$ wurden im Seminalplasma infertiler Patienten auf klinischer Ebene nachgewiesen (Fujisawa et al. 1998). Leider fehlt bei vielen Studien eine Korrelation mit verlässlichen Entzündungsparametern, so dass eine Interpretation der Ergebnisse schwierig ist.

Andere Zytokine und Wachstumsfaktoren •

- Transforming growth factor $\beta$ (TGF $\beta$ ) gehört zu einer Familie von Wachstumsfaktoren, von welcher drei Vertreter in Säugetieren exprimiert werden $\left(\beta_{1}, \beta_{2}, \beta_{3}\right)$. TGF $\beta$ stellt dabei einen Vertreter einer Superfamilie von Proteinen dar, die Proteine wie Inhibin, Activin und Anti-Mullerian-Hormon beinhaltet. TGF $\beta$ ist ein ubiquitärer Wachstumsfaktor mit sehr vielfältigen Funktionen. Die Bedeutung im Rahmen urogenitaler Infektionen ist bisher wenig untersucht und auf klinischer Ebene völlig unklar. In Leydigzellen downreguliert TGF $\beta$ die Expression des LH-Rezeptors (Rezeptor für Luteinisierendes Hormon), die Bildung des "Second Messengers“ cAMP sowie die Steroidbiosynthese direkt via Suppression von $\mathrm{P}_{450 c 17}$ (Saez und Lejeune 1996).

- Tierexperimentell konnte durch TGF $\beta_{1}$ und $\beta_{2}$ in supraphysiologischen Konzentrationen Apoptose in Spermatogonien und Spermatozyten erzeugt werden, während Sertoli-Zellen unbeeinflusst blieben (Gautier et al. 1997).

- Epidermal growth factor (EGF) scheint nur für die Regulation der Spermatogenese eine Rolle zu spielen. Eine Korrelation der Expression von EGF in Sertoli-Zellen und Defekten in der Spermatogenese von infertilen Patienten wurden beschrieben (Nakazumi et al. 1996).

- Der Wachstumsfaktor Hepatocyte growth factor/Scatter factor (HGF/ SF) findet sich in erhöhter Konzentration im Seminalplasma bei Vorliegen 
einer Ejakulatinfektion. Eine Wirkung auf spezifische Spermatozoenfunktionen ist unbekannt. Methodische Schwierigkeiten (ELISA versus Bioassay) erschweren zudem Studien und Interpretationen (Depuydt et al. 1998).

\section{Reaktive Sauerstoffverbindungen (ROS)}

Reaktive Sauerstoffverbindungen finden sich im Rahmen von Ejakulatinfektionen in erhöhter Konzentration im Seminalplasma. Dabei korrelieren ROS mit der Vermehrung von proinflammatorischen Zytokinen im Ejakulat. Der Begriff ROS (reactive oxygen species) fasst verschiedene reaktive Sauerstoffverbindungen zusammen, welche sich allesamt durch die Fähigkeit auszeichnen, andere Moleküle durch Elektronenaufnahme zu oxidieren. Die Halbwertszeit der einzelnen reaktiven Sauerstoffverbindungen liegt dabei im Millisekundenbereich, und aufgrund ihrer elektrischen Ladung sind die meisten ROS nicht in der Lage, Plasmamembranen zu überwinden (Ochsendorf 1998). Eine wichtige Ausnahme bildet Wasserstoffperoxid $\left(\mathrm{H}_{2} \mathrm{O}_{2}\right)$, welches nach Sekretion und Diffusion intrazellulär wirken kann. Es darf dabei nicht vergessen werden, dass ROS permanent durch metabolische Prozesse in allen Zellen gebildet werden, zumeist sequestert in Organellen. Vor allem der Energiemetabolismus in Mitochondrien produziert permanent zelleigene ROS als Beiprodukte. Zelleigene Strukturen werden dabei durch effiziente Antioxidatiensysteme vor der deletären Wirkung dieser Substanzen geschützt (Ochsendorf 1998; Ochsendorf et al. 1998). Diese Systeme sind im Wesentlichen Elektronendonatoren (Vitamin C, Vitamin E etc.) sowie Enzymsysteme (Glutathionperoxidase, Superoxiddismutase).

Für den Bereich der urogenitalen Infektionen sind vor allem ROS von Bedeutung, welche von Makrophagen und segmentkernigen Granulozyten nach Erregerkontakt freigesetzt werden (oxidative burst). Im Hoden finden sich dabei Leydig-Zellen in unmittelbarer Nachbarschaft von residenten, testikulären Makrophagen und bilden potentiell ein Ziel für ROS (Hales et al. 1999). Die Wirkungen von ROS auf molekulare Funktionen von Leydig-Zellen und Ger-

\section{Urologie}

minalepithel werden derzeit intensiv erforscht, zumal ROS nicht nur für entzündliche Erkrankungen von Bedeutung sind, sondern auch wesentliche Funktionen im Rahmen anderer pathophysiologischer Situationen wie Alterungsprozess, Reperfusion nach Ischämie und Varikozele zu übernehmen scheinen.

ROS im Seminalplasma stammen vor allem von segmentkernigen Leukozyten, welche die Mehrheit der Ejakulatleukozyten darstellen (Whittington u. Ford 1999). Das Seminalplasma verfügt dabei interessanterweise über erhebliche antioxidative Kapazitäten, die jedoch bei einer Aktivierung vorhandener Leukozyten oder bei der Vermehrung von Ejakulatleukozyten überlastet scheinen (Ochsendorf 1998). ROS oxidieren nach Freisetzung Lipide der Plasmamembranen von Spermatozoen, was schliesslich zu einer Veränderung der Lipidkomposition zugunsten gesättigter Fettsäuren führt. Die resultierende erhöhte Rigidität der Plasmamembran ist vermutlich die molekulare Basis für Veränderungen der Spermatozoenmotilität (Zalata et al. 1998). Nach Passage der Plasmamenbran können ROS auch Wirkungen auf intrazelluläre Moleküle ausüben. Eine bekannte Wirkung von ROS ist die Veränderung des elektrochemischen mitochondrialen Gradienten, welcher die Basis für Elektronentransport und die Synthese von ATP darstellt (Armstrong et al. 1999). Dauerhafte Beeinflussung von mitochondrialer Funktion führt zu profunder Beeinträchtigung der Zellfunktion durch Energiemangel. An experimentell behandelten Spermatozoen konnte gezeigt werden, dass ROS von $7 \times 10^{6}$ aktivierten Ejakulatleukozyten/ml signifikante Wirkung auf die Synthese von ATP und auf die Spermatozoenmotilität haben (Armstrong et al. 1999).

Oxidation akrosomaler Strukturen führt ebenfalls $\mathrm{zu}$ einer Beeinträchtigung der Akrosomenfunktion, welche zu verminderter reproduktiver Kapazität der Spermatozoen führt (Whittington et al. 1999; Ichikawa et al. 1999).

\section{Seminale Spermatozoenantikörper (ASA)}

Spermatozoenantikörper können im Serum und im Seminalplasma von Patienten mit und ohne urogenitalen Infek- tionen nachgewiesen werden. Nach allgemeiner Überzeugung spielen dabei Spermatozoenantikörper im Serum eine untergeordnete Rolle in Bezug auf Fertilitätsstörungen (Eggert-Kruse et al. 1998). In neueren Arbeiten hat sich zudem keine Korrelation von symptomatischen und asymptomatischen urogenitalen Infektionen und dem Nachweis von seminalen ASA ergeben (Habermann und Krause 1999; Munuce et al. 1999). Dies gilt sowohl für ASA vom IgG als auch vom IgM Typ. Desgleichen konnte eine Korrelation zwischen ASA und Entzündungsmarkern wie der Granulozytenelastase, Leukozytenzahlen und mikrobiologischen Befunden nicht nachgewiesen werden (EggertKruse et al. 1998). Allenfalls mag in der urogenitalen Infektion der Auslöser für die Bildung von ASA liegen, wenn im Rahmen von akuten Infektionen antigenes Spermatozoenmaterial dem Immunsystem exponiert wird (EggertKruse et al. 1998).

\section{Urogenitale Infektionen und assistierte Reproduktion (ART)}

Für den Bereich der assistierten Reproduktionverfahren (ART, artificial reproductive technologies) gelten in vielerlei Hinsichten andere Voraussetzungen als für In-vivo-Situationen. Spermatozoen von Patienten im Rahmen von IVF und ICSI durchlaufen einen Aufarbeitungsprozess, welcher wesentliche Faktoren der urogenitalen Infektion überwiegend eleminiert: Bakterien, Leukozyten und leukozytäre ROS und Zytokine. Zum anderen erfolgt die Aufarbeitung von Spermatozoen in der Regel in antibiotisch gepufferten Medien, so dass auch hier eine bakterielle Kontamination auf dieser Ebene blockiert wird (Michelmann 1998).

Auch wenn die Aussagen klinischer Studien zum Problem der ART und urogenitalen Infektion insgesamt widersprüchlich sind, kann gefolgert werden, dass Infektionen per se für den Erfolg von ART eine untergeordnete Rolle spielen (Michelmann 1998).

Diese Feststellung schließt aber keinesfalls die infektiologische Untersuchung von Fertilitatspatienten und, bei Vorliegen einer urogenitalen Infektion, eine konsequente antibiotische Therapie aus. Ein soches Vorgehen dürfte dem allgemeinen Standard der Therapie 
der männlichen Infertilität entsprechen (Weidner et al. 1998).

\section{Schlussfolgerungen und Hinweise für die Praxis}

In zukünftigen Studien werden die Auswirkungen spezifischer, definierter urogenitaler Infektionen auf die männliche reproduktive Kapazität untersucht werden müssen. Dabei werden sicherlich innovative Parameter wie Zytokine und ROS Berücksichtigung finden. Internationale und allgemein akzeptierte Klassifikationen und diagnostische Standards ermöglichen dabei eine gute Vergleichbarkeit von Patientendaten.

Wesentliche Erkenntnisse sind aus experimentellen Studien zu erwarten, welche klinisch pathophysiologische Konditionen simulieren können und somit eine Vergleichbarkeit mit realen klinischen Infektionen möglich machen. Inwieweit Infektionen des Urogenitaltraktes Auswirkungen auf die Spermatogenese, Steroidbiosynthese und Funktion von Spermatozoen haben, wird dabei eine zentrale Frage sein. Konzepte zur Erklärung dieser Mechanismen sind existent, sind jedoch zum gegenwärtigen Zeitpunkt noch nicht in experimentellen Modellen etabliert, welche mit Urogenitalinfektionen von Patienten zu vergleichen wären.

\section{Literatur}

Aitken RJ, Baker HW (1995) Seminal leukocytes: passengers, terrorists or good samaritans? Hum Reprod 10: 1736-1739

Appell RA, Evans PR (1978) The effect of temperature on sperm motility. II. Is bacterial growth a factor? Fertil Steril 30: 436-438

Armstrong J S, Rajasekaran M, Chamulitrat W, Gatti P, Hellstrom WJ, Sikka SC (1999) Characterization of reactive oxygen species induced effects on human spermatozoa movement and energy metabolism. Free Radic Biol Med 26: 869-880

Auroux M R, Jacques L, Mathieu D, Auer J (1991) Is the sperm bacterial ratio a determining factor in impairment of sperm motility: an in-vitro study in man with Escherichia coli. Int J Androl 14: 264-270

Bisson JP, Czyglik F (1974) Effect of genito-urinary infection on the spermatozoa (author's transl.) J Urol Nephrol (Paris) 80: 631-635

Borden EC (1992) Interferons: pleiotropic cellular modulators. Clin Immunol Immunopathol 62: $18-24$
Bosmann HB, Hales KH, Li X, Liu Z, Stocco DM, Hales DB (1996) Acute in vivo inhibition of testosterone by endotoxin parallels loss of steroidogenic acute regulatory (StAR) protein in Leydig cells. Endocrinology 137: 4522-4525

Bussiere JL, Hardy LM, Hoberman AM, Foss JA, Christian MS (1996) Reproductive effects of chronic administration of murine interferon-gamma. Reprod Toxicol 10: 379-391

Caldamone AA, Cockett AT (1978) Infertility and genitourinary infection. Urology 12: 304-312

Caldamone AA, Emilson LBV, Al-Juburi A, Cockett ATK (1984) Prostatitis: prostatic secretory dysfunction affecting fertility. Fertil Steril 34: $602-603$

Cerami A (1992) Inflammatory cytokines. Clin Immunol Immunopathol 62: 3-10

Chang MW, Choi TK, Matsuo Y, Yoshii Z (1984) Influence of Ureaplasma urealyticum and Mycoplasma hominis on the human spermatozoal motility. Hiroshima J Med Sci 33: $23-26$

Christiansen E, Tollesfrud A, Purvis K (1991) Sperm qyuality in men with chronic abacterial prostatovesiculitis verified by rectal ultrasonography. Urology 38: 545-549

Cintron RD, Wortham Jr. JW, Acosta A (1981) The association of semen factors with the recovery of Ureaplasma urealyticum. Fertil Steril 36: 648-652

Cohen PE, Pollard JW (1998) Normal sexual function in male mice lacking a functional type I interleukin-1 (IL-1) receptor. Endocrinology 139: 815-818

Comhaire F, Verschraegen G, Vermeulen L (1980) Diagnosis of accessory gland infection and its possible role in male infertility. Int J Androl 3: 32-45

del Porto GB, Derrick FC Jr, Bannister ER (1975). Bacterial effect on sperm motility. Urology 5: 638-639

Denison FC, Grant VE, Calder AA, Kelly RW (1999) Seminal plasma components stimulate interleukin- 8 and interleukin-10 release. Mol Hum Reprod 5: 220-226

Depuydt C, Zalata A, Christophe A, Mahmoud A, Comhaire $F$ (1998) Mechanisms of sperm deficiency in male accessory gland infection. Andrologia 30 [Suppl 1]:29-33

Desai S,Cohen S, Khatamee M, Leiter E (1980) Ureaplasma urealyticum ( $T$-mycoplasma) infection: does it have a role in male infertility? J Urol 124: 469-471

Diemer T, Desjardins C (1999) Developmental and genetic disorders in spermatogenesis. Hum Reprod Update 5: 120-140

Diemer T, Desjardins C (1999) Disorders of Spermatogenesis. In: Knobil E, Neill JD (eds) Encyclopedia of Reproduction 4. Academic Press, San Diego New York London, pp 546-555

Diemer T, Weidner W, Michelmann HW, Schiefer HG, Rovan E, Mayer F (1996) Influence of Escherichia coli on motility parameters of human spermatozoa in vitro. Int J Androl 19: $271-277$
Dik P, Lock TM, Schrier BP, Zeiljemaker B, Boon TA (1996) Transurethral marsupialization of a medial prostatic cyst in patients with prostatitis-like symptoms. J Urol 155: 1301-1304.

Drach GW, Fair WR, Meares EM, Stamey TA (1978) Classification of benign diseases associated with prostatic pain: prostatitis or prostatodynia? J Urol 120: 266

Eggert-Kruse W, Bellmann A, Rohr G, Tilgen W, Runnebaum B (1992) Differentiation of round cells in semen by means of monoclonal antibodies and relationship with male fertility. Fertil Steril 58: 1046-1055

Eggert-Kruse W, Gerhard I, Naher H, Tilgen W, Runnebaum B (1990) Chlamydial infection-a female and/or male infertility factor? Fertil Steril 53: 1037-1043

Eggert-Kruse W, Rohr G, Probst S et al. (1998) Antisperm antibodies and microorganisms in genital secretions-a clinically significant relationship? Andrologia 30 [Suppl]:61-71

Fowlkes DM, Dooher GB, 0,Leary WM (1975) Evidence by scanning electron microscopy for an association between spermatozoa and T-mycoplasmas in men of infertile marriage. Fertil Steril 26: 1203-1211

Fujisawa M, Fujioka H, Tatsumi N, Inaba Y, Okada H, Arakawa S, Kamidono S (1998). Levels of interferon alpha and gamma in seminal plasma of normozoospermic, oligozoospermic, and azoospermic men. Arch Androl 40: 211-214

Gautier C, Levacher C, Saez, JM, Habert R (1997) Expression and regulation of transforming growth factor beta 1 mRNA and protein in rat fetal testis in vitro. Biochem Biophys Res Commun 236: 135-139

Giamarellou H,Tympanidis K, Bitos NA, Leonidas E, Daikos GK (1984) Infertility and chronic prostatitis. Andrologia 16: 417-422

Gnarpe H, Friberg J (1972) Mycoplasma and human reproductive failure. I. The occurrence of different Mycoplasmas in couples with reproductive failure. Am J Obstet Gynecol 114: 727-731

Grossgebauer K, Hennig A, Hartmann D (1977) Mycoplasma induced damage to sperm head in infertile men. Hautarzt 28: 299-302

Guo H, Calkins JH, Sigel MM, Lin T (1990) Interleukin-2 is a potent inhibitor of Leydig cell steroidogenesis. Endocrinology 127: 1234-1239

Habermann B, Krause W (1999) Altered sperm function or sperm antibodies are not associated with chlamydial antibodies in infertile men with leucocytospermia. J Eur Acad Dermatol Venereol 12: 25-29

Haidl G (1990). Macrophages in semen are indicative of chronic epididymal infection. Arch Androl 25: 5-11

Hales DB, Diemer T, Hales KH (1999) Role of cytokines in testicular function. Endocrine 10: 201-217 
Hargreave TB, Torrance M, Young H, Harris AB (1982) Isolation of ureaplasma urealyticum from seminal plasma in relation to sperm antibody levels and sperm motility. Andrologia 14: 223-227

Hibi H, Yokoi K, Yamamoto M (1997) Effects of alpha-interferon on sperm production, concentration, and motility in the rat. Int J Urol 4: 603-607

Hill JA, Anderson DJ (1992) Tumor necrosis factoralpha and sperm function? Fertil Steril 57: 705-707

Hofmann N, Haider SG (1985) New results in the morphologic diagnosis of spermatogenesis disorders. Gynakologe 18: 70-80

Hofstetter A, Schmiedt E, Schill WB, Wolff HH (1978) Genital mycoplasma strains as a cause of male infertility. Helv Chir Acta 45: 329-333

Huaijin C, Junyan Z, Naigun C (1998) Prostatic fluid and sperm examination:106 cases. Priliminary study on infertility. Act Urol Belg 66: 19-21

Huwe P, Diemer T, Ludwig M, Liu J, Schiefer HG, Weidner W (1998) Influence of different uropathogenic microorganisms on human sperm motility parameters in an in vitro experiment. Andrologia 30 [Suppl 1]:55-59

Ichikawa T, Oeda T, Ohmori H, Schill WB (1999) Reactive oxygen species influence the acrosome reaction but not acrosin activity in human spermatozoa. Int J Androl 22: 37-42

Ingerslev HJ, Walter S, Andersen JT et al. (1986) A prospective study of antisperm antibody development in acute epididymitis. J Urol 136: 162-164

Jacques L, Mathieu D, Auer J, Auroux M (1990) Effect of urogenital infections on sperm parameters and hypofertility in man. Biomed Pharmacother 44: 225-228

JarowJP, Kirkland JA Jr, Assimos DG (1990) Association of antisperm antibodies with chronic nonbacterial prostatitis. Urology 36: 154-156

Jarow JP, Sanzone JJ (1992) Risk factors for male partner antisperm antibodies. J Urol 148: 1805-1807

Jonsson CK, Zetterstrom RH, Holst M, Parvinen M, Soder 0 (1999) Constitutive expression of interleukin-1alpha messenger ribonucleic acid in rat Sertoli cells is dependent upon interaction with germ cells. Endocrinology 140: 3755-3761

Kim FY, Goldstein M (1999) Antibacterial skin preparation decreases the incidence of false- positive semen culture results. J Urol 161: 819-821

Kohn FM, Erdmann I, Oeda T, El Mulla KF, Schiefer HG, Schill WB (1998) Influence of urogenital infections on sperm functions. Andrologia 30 [Suppl 1]:73-80

Koumantakis E, Matalliotakis I, Kyriakou D, Fragouli Y, Relakis K (1998) Increased levels of interleukin-8 in human seminal plasma. Andrologia 30: 339-343

Krieger JN, Berger RE, Ross S0, Rothmann I, Muller CH (1996) Seminal fluid findings in men with nonbacterial prostatitis and prostatodynia. J Androl 17: 310-318
Krieger JN, Hooton TM, Brust PJ, Holmes KK, Stamm WE (1988) Evaluation of chronic urethritis. Defining the role for endoscopic procedures. Arch Intern Med 148: 703-707

Leib Z, Bartoov B, Eltes F, Servadio C (1994) Reduced semen quality caused by chronic abacterial prostatitis:an enigma or reality? Fertil Steril 61: 1109-1116

Levy R, Layani-Milon MP, Giscard D,Estaing S, Najioullah F, Lornage J, Aymard M, Lina B (1999) Screening for Chlamydia trachomatis and Ureaplasma urealyticum infection in semen from asymptomatic male partners of infertile couples prior to in vitro fertilization. Int J Androl 22: 113-118

Li X, Hales KH, Watanabe G, Lee RJ, Pestell RG, Hales DB (1997) The effect of tumor necrosis factor-alpha and CAMP on induction of AP-1 activity in MA-10 tumor Leydig cells. Endocrine 6: 317-324

Ludwig M, Kummel C, Schroeder-Printzen I, Ringert RH, Weidner W (1998) Evaluation of seminal plasma parameters in patients with chronic prostatitis or leukocytospermia. Andrologia 30 [Suppl 1]:41-47

Ludwig M, Schroeder-Printzen I, Lüdecke G, Weidner W (2000) Comparison of expressed prostatic secretions with urine after prostatic massage - a means to diagnose chronic prostatitis and inflammatory chronic pelvic pain syndrome. Urology 55: (in press)

Mahmoud AM, Geslevich J, Kint J, Depuydt C, Huysse L, Zalata A, Comhaire FH (1998) Seminal plasma alpha-glucosidase activity and male infertility. Hum Reprod 13: 591-595

Makler A, Urbach Y, Lefler E, Merzbach D (1981) Factors affecting sperm motility. VI. Sperm viability under the influence of bacterial growth in human ejaculates. Fertil Steril 35: 666-670

Mardh PA, Ripa KT, Colleen S, Treharne JD, Darougar S (1978) Role of Chlamydia trachomatis in non-acute prostatitis. Br J Vener Dis 54: $330-314$

Meares EM, Stamey TA (1968) Bacteriologic localization patterns in bacterial prostatitis and urethritis. Invest Urol 5: 492-518

Menkveld R, Kruger TF (1998) Sperm morphology and male urogenital infections. Andrologia 30 [Suppl 1]: 49-53

Michelmann HW (1998) Influence of bacteria and leukocytes on the outcome of in vitro fertilization (IVF) or intracytoplasmic sperm injection (ICSI). Andrologia 30 [Suppl 1]: 99-101

Muciaccia B, Uccini S, Filippini A, Ziparo E, Paraire F, Baroni CD, Stefanini M (1998) Presence and cellular distribution of HIV in the testes of seropositive subjects: an evaluation by in situ PCR hybridization. Faseb J 12: 151-163

Muller CH, Coombs RW, Krieger JN (1998) Effects of clinical stage and immunological status on semen analysis results in human immunodeficiency virus type 1-seropositive men. Andrologia 30 [Suppl 1]:15-22
Munuce MJ, Bregni C, Carizza C, Mendeluk, G (1999) Semen culture, leukocytospermia, and the presence of sperm antibodies in seminal hyperviscosity. Arch Androl 42: 21-28

Nakazumi H, Sasano H, Maehara I, Orikasa S (1996) Transforming growth factor-alpha, epidermal growth factor, and epidermal growth factor receptor in human testis obtained from biopsy and castration: immunohistochemical study. Tohoku J Exp Med 178: 381-388

Nickel JC (1998) Prostatitis: myths and realities. Urology 51: 362-366

Nunez-Calonge $\mathrm{R}$, Caballero $\mathrm{P}$, Redondo C, Baquero $\mathrm{F}$ Martinez-Ferrer M, Meseguer MA (1998) Ureaplasma urealyticum reduces motility and induces membrane alterations in human spermatozoa. Hum Reprod 13: 2756-2761

Ochsendorf FR (1998) Infection and reactive oxygen species. Andrologia 30 [Suppl 1]: 81-86

Ochsendorf FR, Buhl R, Bastlein A, Beschmann $\mathrm{H}$ (1998) Glutathione in spermatozoa and seminal plasma of infertile men. Hum Reprod 13: 353-359

Orava M, Cantell K, Vihko R (1986) Treatment with preparations of human leukocyte interferon decreases serum testosterone concentrations in men. Int J Cancer 38: 295-296

Osegbe DN (1991) Testicular function after unilateral bacterial epididymo-orchitis. Eur Urol 19: 204-208

Paulson JD, Polakoski KL (1977) Isolation of a spermatozoal immobilization factor from Escherichia coli filtrates. Fertil Steril 28: 182-185

Saez JM, Lejeune H (1996) Regulation of Leydig cell functions by hormones and growth factors other than LH and IGF-1. In:Payne AH, Hardy MP, Russell LD (eds). The Leydig Cell. Cache River Press, Vienna, IL (USA), pp 383-406

Sam AD 2nd, Sharma AC, Lee LY, Hales DB, Law WR, Ferguson JL, Bosmann HB (1999) Sepsis produces depression of testosterone and steroidogenic acute regulatory (StAR) protein. Shock 11: 298-301

Sanchez R, Villagran E, Concha M, Cornejo R (1989) Ultrastructural analysis of the attachment sites of Escherichia coli to the human spermatozoon after in vitro migration through estrogenic cervical mucus. Int J Fertil 34: 363-367

Schaeffer AJ (1998) Aetiopathology and pathogenesis of urogenital infections. Andrologia 30 [Suppl 1]:3-6

Schaeffer AJ (1999) Prostatitis: US perspective. Int J Antimicrob Agents 11: 205-211

Schiefer HG (1998) Microbiology of male urethroadnexitis:diagnostic procedures and criteria for aetiologic classification. Andrologia 30 [Suppl 1]:7-13

Schiefer HG, Jantos C, Weidner W (1994) Urethroadnexitis in the man and acute urethral syndrome in the woman. Microbiological and immunologic studies of etiologic classification. Urologe A 33: 188-195 
Schirren C, Zander HA (1966) Genital infections in men and their effects on spermatozoa motility. Med Welt 1: 45-47

Soffer Y, Ron-El R, Golan A, Herman A, Caspi E, Samra $Z$ (1990) Male genital mycoplasmas and Chlamydia trachomatis culture: its relationship with accessory gland function, sperm quality, and autoimmunity. Fertil Steril 53: 331-336

Stone SC, de la Maza LM, Peterson EM (1986) Recovery of microorganisms from the pelvic cavity after intracervical or intrauterine artificial insemination. Fertil Steril 46: 61-65

Swenson CE, Toth A, O'Leary WM (1979) Ureaplasma urealyticum and human infertility: the effect of antibiotic therapy on semen quality. Fertil Steril 31: 660-665

Teague NS, Boyarsky S, Glenn JF (1971) Interference of human spermatozoa motility by Escherichia coli. Fertil Steril 22: 281-285

Trum JW, Mol BW, Pannekoek Y, Spanjaard L, Wertheim P, Bleker OP, van der Veen F (1998) Value of detecting leukocytospermia in the diagnosis of genital tract infection in subfertile men. Fertil Steril 70: 315-319

Tuttle Jr JP, Bannister ER, Derrick FC (1977) Interference of human spermatozoal motility and spermatozoal agglutination by Candida albicans. J Urol 118: 797-799
Vicari E (1999) Seminal leukocyte concentration and related specific reactive oxygen species production in patients with male accessory gland infections. Hum Reprod 14: 2025-2030

Weidner W, Garbe C, Weissbach L, Harbrecht J, Kleinschmidt K, Schiefer HG, Friedrich HJ (1990) Initial therapy of acute unilateral epididymitis using ofloxacin. II. Andrological findings. Urologe A29: 277-280

Weidner W, Jantos C, Schiefer HG, Haidl G, Friedrich HJ (1991) Semen parameters in men with and without proven chronic prostatitis. Arch Androl 26: 173-183

Weidner W, Krause W, Ludwig M (1999) Relevance of male accessory gland infection for subsequent fertility with special focus on prostatitis. Hum Reprod Update 5: 421-432

Weidner W, Krause W, Schiefer HG, Brunner H, Friedrich HJ (1985) Ureaplasmal infections of the male urogenital tract, in particular prostatitis, and semen quality. Urol Int 40: 5-9

Weidner W, Ludwig M, Miller J (1998) Therapy in male accessory gland infection-what is fact, what is fiction?" Andrologia 30 [Suppl 1]:87-90

Weidner W, Schiefer HG, Krauss H, Jantos C, Friedrich HJ, Altmannsberger M (1991) Chronic prostatitis: a thorough search for etiologically involved microorganisms in 1,461 patients. Infection 19 [Suppl 3]:119-125

Whittington K, Ford WC (1999) Relative contribution of leukocytes and of spermatozoa to reactive oxygen species production in human sperm suspensions. Int J Androl 22: $229-235$
Whittington K, Harrison SC, Williams KM, Day JL, McLaughlin EA, Hull MG, Ford WC (1999) Reactive oxygen species (ROS) production and the outcome of diagnostic tests of sperm function. Int J Androl 22: 236-242

WHO (1992) WHO laboratory manual for examination of human semen and semen-cervical mucus interactio. Cambridge University Press, Cambridge New York

WHO (1993) WHO manual for the standardized investigation and diagnosis of the infertile couple. Cambridge University Press, Cambridge, pp 37-38

Witkin SS, Jeremias J, Grifo JA, Ledger WJ (1993) Detection of Chlamydia trachomatis in semen by the polymerase chain reaction in male members of infertile couples. Am J Obstet Gynecol 168: 1457-1462

Wolff HH, Panhans A, Stolz W, Meurer M (1993) Adherence of Escherichia coli to sperm: a mannose mediated phenomenon leading to agglutination of sperm and E. coli. Fertil Steril 60: 154-158

Xu C, Sun GF, Zhu YF, Wang YF (1997) The correlation of Ureaplasma urealyticum infection with infertility. Andrologia 29: 219-226

Zalata AA, Christophe AB, Depuydt CE, Schoonjans F, Comhaire FM (1998) White blood cells cause oxidative damage to the fatty acid composition of phospholipids of human spermatozoa. Int J Androl 21: 154-162 